Computer Applications: An International Journal (CAIJ), Vol.3, No.1, February 2016

\title{
ANyone Can Talk ToOL
}

\author{
Mohammad Taye, Mohammad Abu Shanab, Moyad Rayyan and Husam Younis
}

\author{
Software Engineering Department \\ Information Technology Faculty \\ Philadelphia University
}

\begin{abstract}
People who have problems with talking, in general, are facing difficulty in communication with others, these disabilities may cause embarrassment to them. Therefore, we have developed a new tool that could help speechless people to share their ideas and conversations with others. This tool will overcome these problems by turning sign language into spoken words, allowing easier communication with others. This project based on hardware device that convert Sign Language to voice. So, the person who cannot speck could be able to use it to transfer his sign to voice. The tool can be used by wearing the special hardware which consists of the smart gloves, a speaker and the interpreter box. Indeed, the sign language only used by speechless people so it's not clear to anyone, so this tool convert the sign language to voice throw smart gloves that will understand the sign, and generate voice throw speaker.
\end{abstract}

\section{KEYWORDS}

Component; sign language, smart gloves, speaker, interpreter.

\section{INTRODUCTION}

There are people with certain disabilities that cause them problems with talking or can't talk at all. These disabilities can cause embarrassment and problems with communicating with others, thus our tool came to help these people by providing them with equipment that allow them to use sign language that they are familiar with and turn it into sounds. This tool will be needed when mute people communicate with other people who don't understand sign language. The tool can be used anywhere and anytime, by wearing the special hardware which consists of the smart gloves, a speaker and the interpreter box.

- Our mission is to in increase the understanding, respect, and equality of mute people.

- Help mute people to talk and express their self to other in order to help them conquer their fears.

- Let and help mute people feel of equality and same treatment.

\section{DOMAIN ANALYSIS}

In this part we make a list of potential classes by finding out the nouns from narrative problem statement and filter out the redundant or irrelevant classes.

1) hand

This class takes the signal from the sensors based on moving fingers. 
Computer Applications: An International Journal (CAIJ), Vol.3, No.1, February 2016

2) Serial Communicator

This class is responsible on reading moves.

3) Move Word Matcher

This class is responsible on matching move with words.

4-Speaker

This class is responsible on speaking word.

Class diagram figure 1 described the structure of a system by showing the system's classes and the relationships among objects.

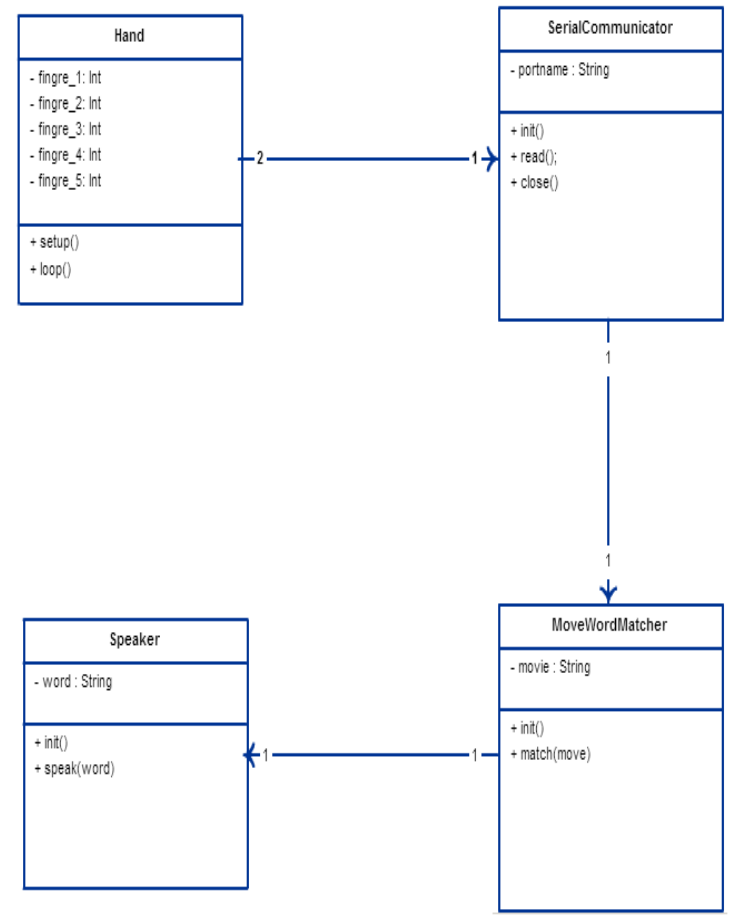

Figure 1: the structure of a system

\section{SEQUENCES DIAGRAM OF THE SYSTEM:}

Figure 2 Sequence Diagram shown how processes operate with one another and in what order, the system has been divided into two sequences diagram 
Computer Applications: An International Journal (CAIJ), Vol.3, No.1, February 2016

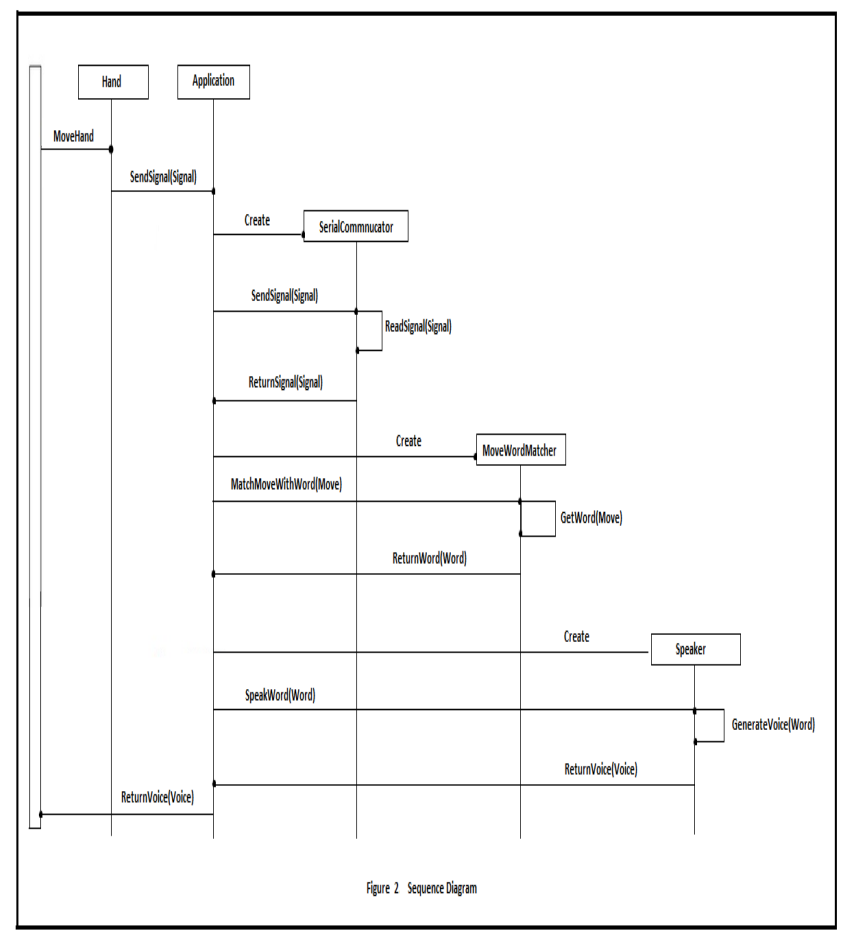

Figure 2: Sequence Diagram

\section{Application Analysis}

This part showed the System Boundary and the system use cases:

The Use Cases of system are:

- Move Gloves: Used to make moves on gloves.

- Generate Voice: Generate voice from move signals.

- Receive signals: To receive signals.

- Send signals: To send signals.

- Matching Signal With Word: match move signal with words that stored on database

- The actors of system are:

- Mute Person: any person will use the system by moving the gloves.

- Gloves: part of the system that's generating signal.

- Interpreter: It's a part of the system that will use the gloves and speakers to generate the sound depending on gloves moves.

- Speakers: part of the system that will create loud voice.

- Database: All words will be stored in this database and will be used when match move signals with words.

Figure 3 illustrate the relationships between actors and use case 
Computer Applications: An International Journal (CAIJ), Vol.3, No.1, February 2016

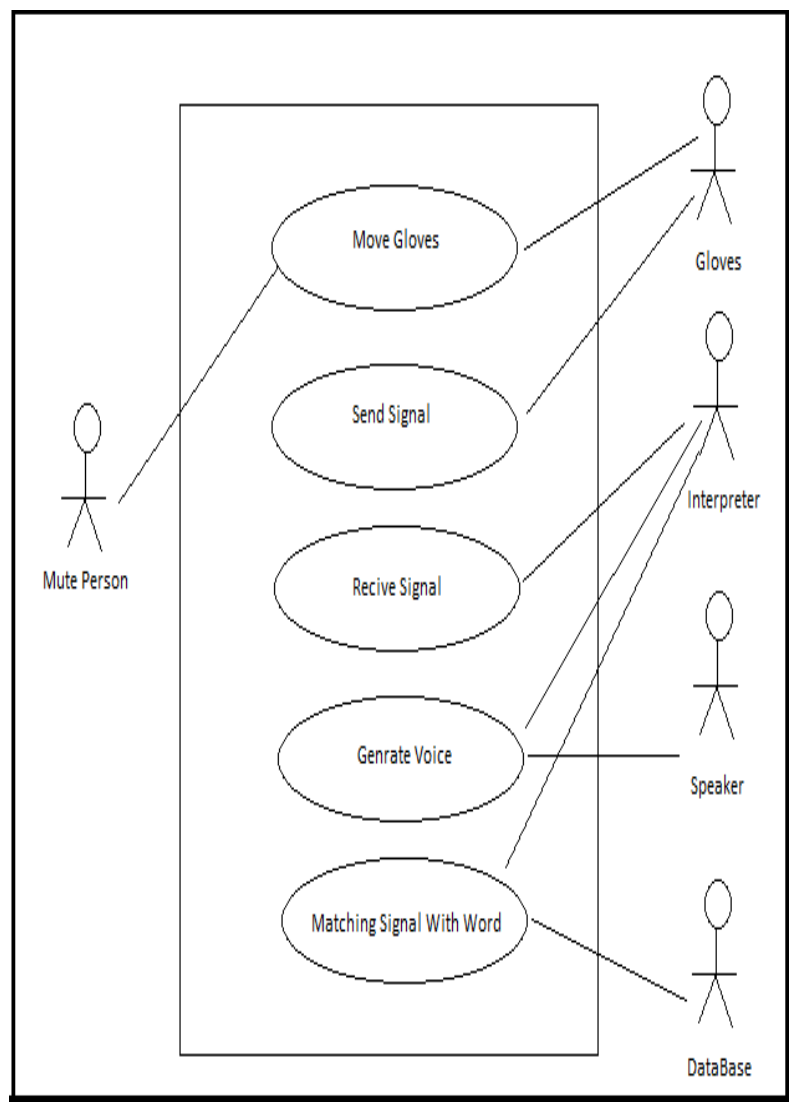

Figure 3: actors and use case

\section{System Flow:}

Figure 4 illustrate the system flow of the system use case

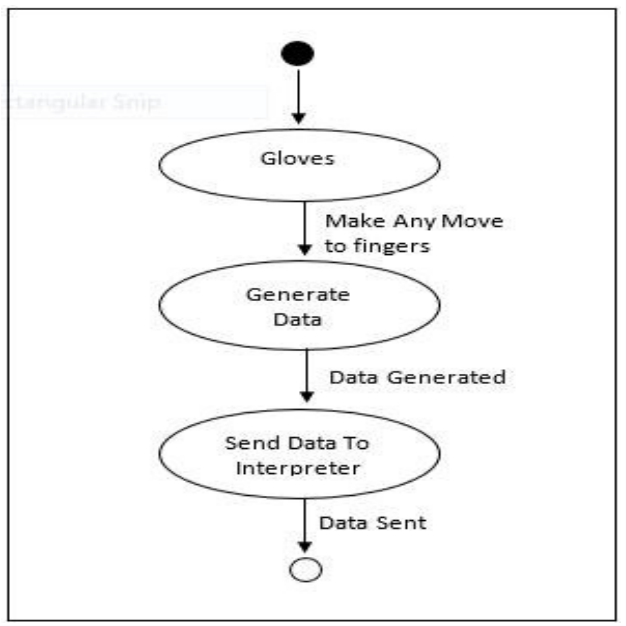

Figure 4: the system flow 


\section{SYSTEM ARCHITECTURE}

Based on our project we decided to divide it into three Layers, which are: The application Layer, The Software System Layer and The Hardware Layer.

Application Layer: Our project contains two applications:

Signal Generator Application: is responsible on generating signal and sending it.

Interpreter Application: is responsible on interpreting signals and generating voice

System Software Layer: Our project contains two-system software:

1-RASPBIAN: is a free operating system based on Debian optimized for the Raspberry Pi hardware. An operating system is the set of basic programs and utilities that make your Raspberry Pi run. However, Raspbian provides more than a pure OS: it comes with over 35,000 packages, pre-compiled software bundled in a nice format for easy installation on your Raspberry Pi.

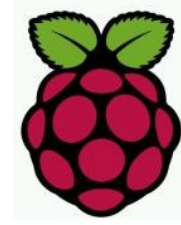

2-ARDUINO: is an open-source electronics prototyping platform based on flexible easy to use hardware and software

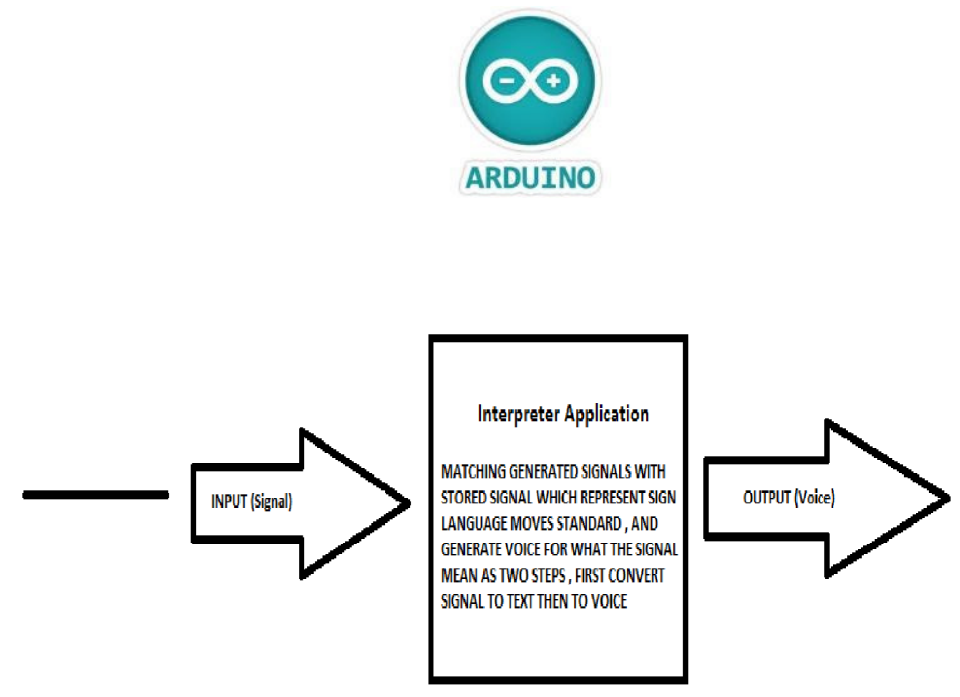

Hardware Layer: Our project consists three main components:

1-Gloves: each glove include five flex sensors each sensor placed on glove finger, and microprocessor connected with these flex sensors 
Computer Applications: An International Journal (CAIJ), Vol.3, No.1, February 2016

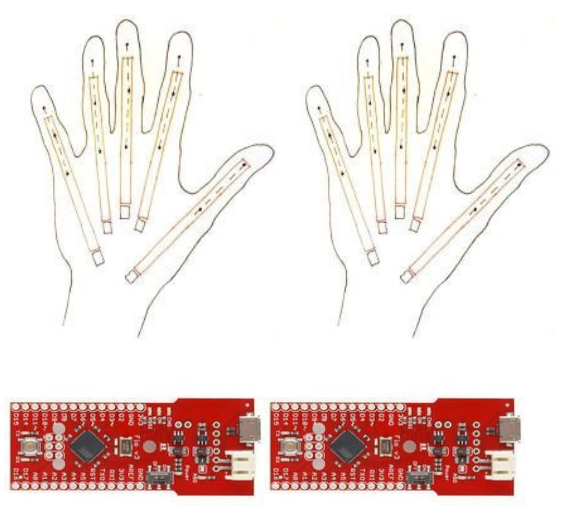

How Connected:

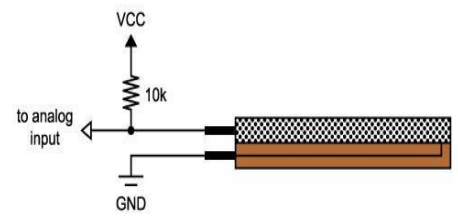

\section{Hardware Used:}

\section{1-Arduino fio v3}

Features:ATmega32U4running at 8MHz,Arduino-CompatibleBootloader,XBeeSocket,Lithium Polymer Battery Compatible,MCP73831TLiPo Charger,Reset button,On/Off Switch 2- Flex Sensor 2.2

2-Interpreter: this is the main microprocessor

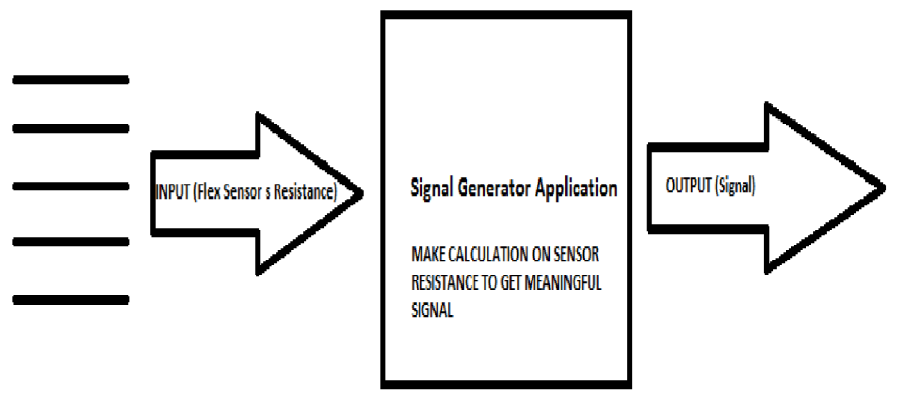


Computer Applications: An International Journal (CAIJ), Vol.3, No.1, February 2016

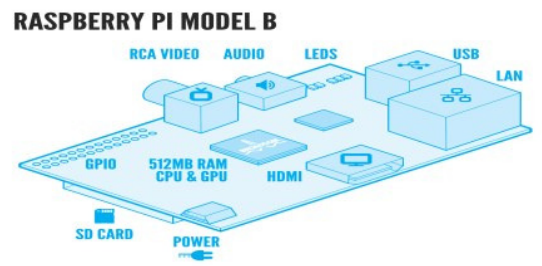

\section{How Connected:}

1-Interpreter Can Be Connected to gloves in Two ways:

A-Wireless

B-Serial communication

2-interpreter connected to speaker using:

A-Bluetooth

\section{Hardware Used:}

\section{1-Rasspbery pi}

Features: Broadcom BCM2835 SoC,700 MHz ARM1176JZF-S core CPU, Broadcom VideoCore IV GPU,512 MB RAM,2 x USB2.0 Ports,Video Out via Composite (PAL and NTSC), HDMI or Raw LCD (DSI),Audio Out via $3.5 \mathrm{~mm}$ Jack or Audio over HDMI,Storage:SD/MMC/SDIO,10/100Ethernet (RJ45),Low-Level Peripherals:,8 8 GPIO,UART,I2C bus,SPIbuswithtwochipselects,+3.3V,+5V,Ground,Power Requirements: 5V @ $700 \mathrm{~mA}$ via MicroUSB or GPIO Header,Supports Debian GNU/Linux, Fedora, Arch Linux, RISC OS and More!

\section{2-Xpee S1 (if Connected Wirelessly )}

Features:3.3V@50mA,250kbps Max data rate,1mW output (+0dBm),300ft (100m) range,Wire antenna,Fully FCC certified,6 10-bit ADC input pins,8 digital IO pins,128-bit encryption,Local or over-air configuration,AT or API command set.

3-Speaker: this component responsible on outputting voice

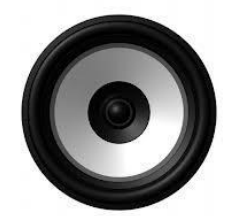

Hardware Used:

Bluetooth Speaker 


\section{USER INTERFACE DESIGN}

In this part presented how the device look like

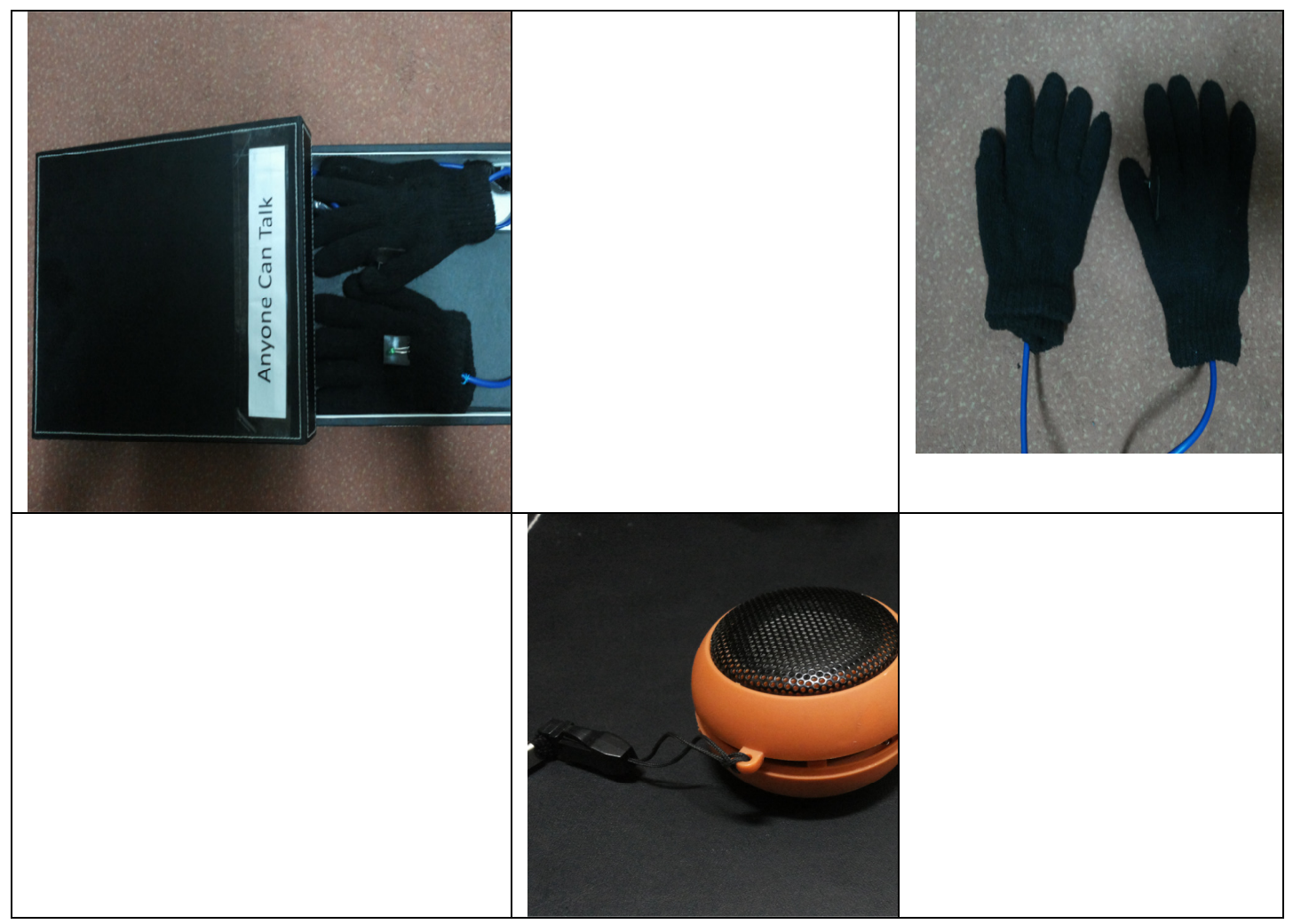

\section{SySTEM TESTING}

\section{A. SMOKe Test :}

Quick test to see if hardware is operational.

Plug the device to the power

Wait until the device is running successfully

Check if there is any smoke of smell coming from the device

Result is: nothing, the device working successfully .

Smoke test is completed

\section{B. Black Box Testing:}

This test is applied on the embedded software that installed on the main process hardware, the received data is generated from the glove, if the finger is raised will send 1 else will send 0 . 
Computer Applications: An International Journal (CAIJ), Vol.3, No.1, February 2016

Table1. Black Box Testing

\begin{tabular}{|c|c|c|}
\hline TEST Number & RECEIVED DATA & TEXT GENERATED \\
\hline Test 1 & 0000011111 & \multicolumn{1}{|l|}{} \\
\hline Test 2 & 0000110000 & السلام عليكم له \\
\hline Test 3 & 1111111111 & $\gamma$ \\
\hline Test 4 & 0110111011 & $\begin{array}{l}\text { Not Registered on } \\
\text { Database }\end{array}$ \\
\hline
\end{tabular}

\section{ACKNOWLEDGMENT}

Anyone can talk project will never be used instead of speaking, but it's a tool that can help speechless people to share their ideas and conversations with other people, the sign language only used by speechless people so its not clear to anyone, so this tool or this device can improve the communication between normal people and speechless people by converting the sign language to voice throw smart gloves that will understand the sign, and generate voice throw speaker .

"Anyone Can Talk Project “ can be further improved by providing easy to use GUI that will let users add some words to the project slandered signs to add new words, also rebuild the project with wireless to be more comfortable and more usable .

\section{REFRENCES}

[1] D.A.Stewart, E.Stewart, J.Little , American sign langugage the easy way ,New York : Barron's Educational series lnc , 2007, PP. 13-209.

[2] M. Banzi and D. Cuartielles (2006) , "Getting Started with Arduino ,Internet ": http://arduino.cc/en/Guide/HomePage [Oct, 30, 2013 ] .

[3] A. Oldknow , B. Lockwood and C. Beale (Dec, 2012). The Raspberry Pi Education Manual (version 1.0) .[online].

Available tp//pi.cs.man.ac.uk/Fdownload/FRaspberry_Pi_Education_Manual.pdf . 